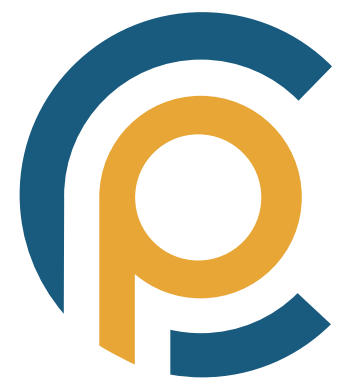

\title{
Educación Propia ¿Es posible una Episteme Raizal-Ancestral Indígena?
}

\author{
Own Education ¿ls an Indigenous \\ Ancestral/Root Episteme Possible?
}

Recibido: 30/06/2020 | Revisado: 21/09/2020 | Aceptado: 24/09/2020 | Publicado: 22/12/2020

Resumen: El artículo presenta una reflexión epistémica sobre la educación propia del pueblo indígena nasa, al norte del Cauca (Colombia). Evidencia de alguna manera que desde las cosmovisiones indígenas también es posible construir conocimiento a partir de los saberes propios y vivencias en los territorios, válidos y legítimos, semejante, al conocimiento occidental moderno y, como apuesta emancipadora de los pueblos indígenas. Se analizaron algunos pilares de la educación propia, destacando su función en procesos de educación autónomos en los territorios, que se consolidaron desde la fundación del Consejo Regional Indígena del Cauca, orientados al fortalecimiento de la identidad cultural, los saberes ancestrales, el idioma propio, la Ley de Origen, la espiritualidad, la autonomía y la resistencia milenaria. De esta manera, la educación propia se constituye más que un proceso para formar estudiantes, en un proyecto político de resistencia, pervivencia física y cultural. Una de las principales características de la educación propia la constituye el posicionamiento de la escuela en, con y para las comunidades mediante los proyectos educativos comunitarios; es decir, hace una educación de la defensa, antisistémica y contextualizada en las condiciones geográficas, ambientales, sociales y económicas de los territorios. De otra parte, se elabora un esbozo de la noción de episteme raizal-ancestral indígena que permite comprender los procesos de construcción de conocimiento desde la misma cosmovisión que la produce.

Palabras clave: autonomía educativa, identidad cultural, descolonización, conocimientos tradicionales.
Abstract: The article presents an epistemic reflection on the proper education of the Nasa indigenous people, north of Cauca (Colombia). It shows that, in some way, from the indigenous worldviews it is also possible to build knowledge from know-how and experiences in the territories, which is valid and legitimate. In the same way as modern Western knowledge does and, as an emancipating process for indigenous peoples. Some pillars of self-education were analyzed, highlighting its role in autonomous education processes in the territories, which were consolidated at the founding of the Regional Indigenous Council of Cauca, aiming for the strengthening of cultural identity, ancestral knowledge, own language, the Law of Origin, spirituality, autonomy, and millennial resistance. In this way, more than a process to train students, self-education is a political project of resistance, physical and cultural pervivience. One of the main characteristics of self-education is the positioning of the school in, with and for the communities through community-oriented educational projects. That is, an education of defense, anti-establishment and contextualized according to the geographical, environmental, social and economic conditions of the territories. Also, a first approximation to the notion of indigenous root-ancestral episteme is developed allowing us to understand the processes of knowledge building from the same worldview that produces it.

Keywords: educational autonomy, cultural identity, decolonization, traditional knowledge. 
Desde 1994 el proceso de escuelas comunitarias indígenas se retomó y extendió a los resguardos de la Zona Norte de Cauca (Colombia), con las estrategias de Proyectos Educativos Comunitarios (en adelante PEC) y el Sistema de Educación Propio Indígena (en adelante SEIP), permitiendo avanzar en la autonomía educativa para implementar los conocimientos tradicionales (ancestrales), a través de propuestas de formación autónoma con metodologías y pedagogías indígenas para manejar los problemas sociales, culturales, económicos y políticos que presentaban los territorios y fortalecer la educación propia, la cual, según el SEIP:

[...] La educación propia se da en cumplimiento de la Ley de Origen, Ley de Vida, Derecho Mayor o Derecho Propio de cada pueblo, manteniendo la unidad, la relación con la naturaleza, con otras culturas, con la sociedad mayoritaria y conservando cada una sus propios usos y costumbres; se desarrolla con base en la sabiduría y conocimiento propio, en forma vivencial, con la participación de sabedores ancestrales, autoridades, mayores, padres de familia y comunidad en general (SEIP, 2013, p. 23).

Como podemos apreciar, hablamos de una propuesta educativa autónoma, liberadora e instituyente; asimismo, la Asociación de Cabildos Indígenas del Norte del Cauca (2005), que tiene como premisa "la colectividad es fuente de la autoridad, la responsabilidad y de la identidad de la cultura" (p. 33). En ese sentido, la educación propia se configura en, con y para la comunidad, como alternativa étnica, diferencial y territorial con temas y prácticas sociales integrados en la cosmovisión ancestral. Sin embargo, el resurgimiento de los PEC, se deben, por una parte, a la necesidad de emanciparse de la educación oficial que, además de imponer la ideología occidental y el cristianismo, desacreditaba los saberes ancestrales. Por otra, más que un proyecto educativo, se configura como proyecto político de resistencia y autonomía epistémica.

Con lo anterior, realizamos una reflexión epistémica sobre la educación propia en relación con la propuesta de Boaventura De Sousa Santos "Una epistemología del sur" (De Sousa, 2009) en el marco de los procesos de educación autónomos que se llevan a cabo en los territorios del pueblo Nasa ${ }^{1}$, destacando los aportes del indígena Manuel Quintín Lame Chantre con la fundación de las primeras escuelas indígenas y los PEC del Consejo Regional Indígena del Cauca (en adelante CRIC), basados en cuatro pilares socioculturales: Ley de Origen, conocimientos ancestrales, idioma propio y espiritualidad, que reivindican la identidad cultural y la autonomía epistémica, que llamo episteme raizal-indígena ancestral en un "ejercicio permanente de análisis sobre los saberes y conocimientos que circulan y que deberían estar presentes en las escuelas" (CRIC, 2004, p. 158).

El artículo ${ }^{2}$ consta de tres partes. La primera, presenta una breve reseña histórica sobre los antecedentes de la educación propia destacando los aportes de Manuel Quintín Lame. La segunda, presentamos los proyectos educativos autónomos, como expresión del potencial epistémico, la resistencia milenaria indígena y la emancipación de la opresión del sistema educativo oficial. Finalmente, presento, uno de los hallazgos de la investigación que denomino episteme raizal-ancestral indígena como el enfoque de la educación propia; seguido, las conclusiones.

Metodología

El abordaje se inscribe en el paradigma interpretativo comprensivo de las prácticas sociales de los sujetos, colectivos y comunidades en diferentes contextos sociohistóricos y culturales, con el propósito de ubicar, las condiciones y factores sociales que inciden en las relaciones intra e intersubjetivas y dialécticas con estructuras dinámicas.

1 La mayor parte de su población se encuentra ubicado en el Departamento del Cauca, Colombia.

2 Este artículo es parte de los resultados de la contribución: Historia de la Educación en el movimiento indígena. Programa de Doctorado en Educación, Universidad Autónoma de Madrid (UAM). 
El trabajo combinó la revisión documental y la interpretación de entrevistas semiestructuradas, observación participante y grupos focales realizados en el cabildo indígena nasa de Bogotá; y, en las experiencias de procesos de educación autónomos en los municipios de Silvia y Toribio, Cauca, en actividades pedagógicas, asambleas educativas y círculos de palabra. El trabajo de campo se realizó entre los años 2017 (febrero a mayo) y 2018 (agosto a octubre). Se trabajó con sabedores/as ${ }^{3}$, consejeros y autoridades indígenas de los procesos educativos autónomos, a fin de conocer los procesos de construcción de los PEC autónomos que fortalecen la identidad cultural.

\section{Breve reseña de la educación propia}

Las primeras escuelas indígenas en Colombia las fundó Manuel Quintín Lame ${ }^{4}$, líder indígena, autodidacta, estratega militar y defensor de los indígenas. A los 18 años prestó servicio militar, tiempo que duró la Guerra de los Mil Días (1901-1903), en el ejército aprendió a leer, escribir y recibió nociones de historia. Después, regresó al Norte del Cauca a trabajar como terrazguero y comprar tierras, pero fracasó en ese intento, época en la cual transitaba el proceso para la disolución del Gran Cauca.

En el norte del Cauca reinaba la opresión contra los indígenas, les quitaban tierras, estafaban, golpeaban y asesinaban; los que trabajan, estaban sometidos al pago de terraje, por parte de la burguesía y los terratenientes del Cauca, situación que incitó a la lucha para defenderse y empezar la recuperación de tierras, pero nuevamente empezaron a ser "víctimas de una campaña de exterminio físico y cultural por parte de la sociedad «blanca», como lo hicieran en su momento la invasión española del siglo XVI, hasta hoy" (Castillo, Presentación libro: las luchas del indio que bajo de la montaña al valle de la civilización, 1976). Es así como la discriminación y el desprecio constituyeron la ideología a superar; la realidad se presentaba de tal manera que, emprende una larga lucha a partir de 1911.

La difusión de sus ideas lo haría con la familia, amigos y terrazgueros que vivían en haciendas circunvecinas, al principio lo escucharon con recelo, cuando vieron que asumía directamente la defensa, presentando demandas ante alcaldes e inspectores de policía cobró credibilidad y fue respaldado por su gente, las parcialidades y luego nombrado representante y defensor general e incito a negarse al pago de terraje. En 1914 viajó a Bogotá y expuso la situación de los indios.

(...) Se entrevistó con Marco Fidel Suárez, en ese momento ministro de Relaciones Exteriores, y con el ministro de Guerra. Por iniciativa del primero de ellos se le facilitó el acceso al Archivo Nacional; allí estudió las cédulas reales de los resguardos, a las cuales se remitiría en futuros escritos. También presentó ante el Congreso las denuncias formuladas por las comunidades paeces de Tierradentro ${ }^{5}$.

Regresó a finales del mismo año, se reunió con los cabildos de Tierradentro, Huila, Tolima, Cauca y Valle para iniciar un levantamiento y conformó el movimiento que se conocería como la quintiniada para recuperar tierras, a quienes les explicó la plataforma de lucha:

, No volver a pagar terrajes.

, Recuperar las tierras perdidas y lograr que los resguardos sean respetados.

, Fortalecer los cabildos.

, Afianzar la cultura indígena.

> Luchar para llegar a formar un "gobierno chiquito" entre los indígenas, que fue su forma de explicar a las comunidades el derecho a la autonomía, a lograr un gobierno propio de las comunidades (CRIC, 2013, p. 110).

\footnotetext{
3 Equivalente a docente en el sistema oficial.

4 Indígena nasa (San Isidro, Cauca, 1880 - Ortega, Tolima, 1967)

5 Recuperado el 17 de marzo de 2018 de https://bit.ly/3dHDu8Yquintin
} 
Con el movimiento se logró reconocer y legalizar algunos resguardos gracias a que encontró la Ley 89 de $1890^{6}$ en los archivos de Bogotá. Lucho alrededor de 18 años en la recuperación de tierras, formuló sus ideas en el texto "los pensamientos del indio de que se educó en las selvas colombianas" (1973); de manera rudimentaria expuso su pensamiento político, la memoria y visión de su lucha, los procesos históricos de los indígenas y temas de educación, inspirado en la naturaleza que llamó fuente de sabiduría. En 1916, crea el programa Luz indígena de Colombia y funda tres escuelas en Ortega, Tolima: "Al principio se abrieron por mí escuelas indígenas en las veredas de Ortega, pero luego estas fueron incendiadas por los blancos" (Quintín Lame, 1973, p. 44). En el programa educativo se destacaban "el libro de la naturaleza, el saber escolar, la agricultura, la ganadería montes, la Higiene, la Metafísica, la Ontología y la Lógica" (Romero, 2006, p. 71), todos basados en su experiencia.

(...) Soy el indio que se educó en la montaña y aprendió a pensar, para pensar en la montaña; (...) pero llegarán a sorprender la historia universal, porque ningún ignorante de que han hablado los hombres que se educaron en la antigüedad, en la edad media y en la contemporánea, todos hablan de sus claustros de educación; por esta razón, yo también debo hablar como lo hago de los claustros donde me educó la Naturaleza; ese Colegio de mi educación (Quintín Lame, 1971, p. 53).

El legado de Quintín Lame, será retomado por el CRIC, su pensamiento político será la base para la nueva plataforma de lucha a la que sumaran otros 7 puntos. La educación indígena será la herramienta política para la concienciación de los pueblos del Cauca, que luego se extenderá a todos los pueblos indígenas de Colombia.

\section{Educación propia: paradigma de resistencia milenaria y lucha de la cultura indígena}

En el Pueblo Nasa la Cosmovisión indígena funge como enfoque filosófico y metodología de auto-indagación y análisis; como filosofía sirvió para re-politizar las ideas y las relaciones políticas con el Estado, frente al derecho a una educación propia oponiéndose al modelo oficial que estaba "divorciada entre la escuela y la política comunitaria, la no valoración de lo indígena, la ausencia de respeto por las autoridades comunitarias" (CRIC, 2004, p. 37). Se rechazó porque vieron subordinada y excluida su cosmovisión por conocimientos occidentales, se evidenciaba en explicaciones sobre los seres vivos, el origen de la vida y la espiritualidad, se les prohibía hablar en lengua nativa, si lo hacían eran severamente castigados, como "forma de dominación colonial" (Maldonado, 2010).

La cosmovisión se entiende como fuente de la educación, "generación de filosofías y epistemologías propias que nutren a nuestro proceso, tanto político como pedagógico" (CRIC, 2004, p. 25). Como metodología de auto-indagación permitió el acercamiento a la historia profunda, revitalizaron la Ley de Origen, la lengua ancestral, los saberes, usos y costumbres y la educación indígena, como inicialmente Ilamaban; en 1978, el CRIC propone el Proyecto de Educación Bilingüe e Intercultural para empezar un proceso de descolonización interna:

(...) Corresponde a una estructura de relaciones sociales de dominio y explotación entre grupos culturales heterogéneos, distintos. Si alguna diferencia específica tiene respecto de otras relaciones de dominio y explotación (ciudad, campo, clases sociales), es la heterogeneidad cultural que históricamente produce la conquista de unos pueblos por otros, y que permite hablar no sólo de diferencias culturales (que existen entre la población urbana y rural y en las clases sociales), sino de diferencias de civilización (González Casanova, 2009, p. 146).

Los pueblos indígenas para ejercer su legítimo derecho a salvaguardar la identidad cultural y mantener la unidad en los territorios, crean el CRIC como estrategia política y social para administrar su patrimonio cultural y como dispositivo para restablecer la educación propia como principal eje político de

6 La columna vertebral de la legislación indigenista colombiana en materia de Resguardos sigue siendo la Ley 89 de 1890, que asegura la estabilidad jurídica de los Resguardos, y reglamenta su organización interna.

7 Benjamín Maldonado propone tres tipos de dominación: colonialismo interno, totalitarismo, etnocidio y manipulación de lo imaginario. 
concienciación cultural y transformar las relaciones con el estado, fue así como, en el $5^{\circ}$ Congreso del CRIC, en 1978, diseñan nuevos objetivos (señalo los de educación):

, Fortalecer la lucha por la cultura y por los cabildos para crear poder para construir y controlar nuestra propia autonomía.

> Crear el programa de educación bilingüe para investigar una propuesta educativa indígena como base de la búsqueda de autonomía.

, Los maestros deben ser bilingües, se debe investigar en las comunidades sobre su historia, cultura; se requiere analizar la situación lingüística y educativa para trazar políticas desde los mismos pueblos.

La educación propia como proyecto político se reafirma introduciendo la autonomía en los PEC, es decir, liberándola de la institucionalidad y posicionándola en, con y para los resguardos y las comunidades, constituyéndola en defensa, resistencia y antisistémica, con metodologías comunitarias para abordar las condiciones contextuales en los territorios; evaluar los impactos nefastos del capitalismo; pues, en la memoria colectiva de los nasa están presente los desastres ecológicos, humanos y económicos desde el año 1845, cuando entraron al territorio los proyectos de desarrollo y por la fiebre de la quina, que llegó con grupos armados, minería, narcotráfico, desplazamiento, etc. En ese sentido, vieron necesario afianzar la conciencia histórica a partir de la cosmovisión que plantea "tres pilares fundamentales: el sueño de formar una comunidad nueva que sepa recoger la tradición propia y al mismo tiempo conjugarla con el futuro, el diálogo con otras culturas y, también, con otras tradiciones" (CRIC, 2004, p. 35). La concienciación histórica parte del presente sin olvidar el pasado para crear futuros a partir de las necesidades del presente como potencialidad; es decir; rompe con "determinaciones para recuperar posibilidades de historización, a partir de su modo de colocarse ante el mundo" (Zemelman, 1998, p. 124).

Expectativas de futuro en la educación propia. Como proyecto político está comprometida a fortalecer los procesos colectivos en la construcción del "Plan de Vida de los pueblos indígenas del Cauca, en tres aspectos fundamentales: los principios filosóficos y políticos, los mandatos de los Congresos y el marco normativo nacional e internacional" (2007, p. 27), orientados a la unidad del pueblo Nasa, restablecer el gobierno propio, las prácticas rituales, la espiritualidad, la familia, la salud, salvaguardar los territorios y mediante la organización colectiva generar estrategias de cambio social positivo para subvertir las relaciones con el estado:

Surge del proceso de la vida colectiva como un hecho que no puede negarse y al que es mucho mejor mirar de frente para entenderlo en lo que realmente es. No es moral ni inmoral, porque su naturaleza no proviene sólo de la dinámica histórica del pasado, sino de la proyección utópica que tiene la acción subversiva hacia el futuro (Fals Borda, 2015, p. 143).

A través de los Planes de Vida trazan horizontes a mediano y largo plazo, han sido ejemplares en su política, con los cuales han ganado dos veces el Premio Nacional de Paz; "el PNUD entregó la máxima distinción del premio Iniciativa Ecuatorial a la comunidad indígena nasa del norte del Cauca, en el marco de la Convención Mundial de Biodiversidad de las Naciones Unidas, celebrada en Kuala Lumpur en 2004" (Wilches-Chaux, 2005, p. 26). No obstante, implementar la educación propia no ha sido fácil; por un lado, se interpone el modelo oficial con leyes y decretos, obstaculizando el desarrollo de la cosmovisión:

Si manejáramos nuestra educación propia nosotros tendríamos que hacerla con un calendario propio que le llamamos El Andar del Tiempo ${ }^{8}$, que está basado en la luna, en el recorrido del año tenemos 21 lunas, y no tenemos doce meses, esa ya es una dificultad, porque nosotros en la normatividad trabajamos diez meses de clase, tenemos distribuidos los tiempos de descanso, vacaciones de los niños en el largo del año, pero esa distribución se hace más en un sentido comercial, de cómo se aporta al comercio dándoles ese tiempo de vacaciones a los estudiantes y a los docentes (entrevista pedagoga nasa, realizada, 2018).

8 También se le llama calendario propio o ecológico. 
El calendario andar del tiempo, descoloniza la educación propia del calendario gregoriano, las actividades se sincronizan con los ciclos lunares, influyendo en aspectos psicobiológicos y culturales en el comportamiento de las comunidades y las relaciones con los territorios y el universo; por ejemplo, la mujer armoniza el ciclo menstrual con actividades de autocuidado y no a otra cosa; los tiempos para cultivo, siembra, cosecha, rituales y mingas se armonizan con las actividades académicas de tal manera que los estudiantes puedan participar.

EI PEC armoniza el andar del tiempo con el cronograma académico: las asignaturas, proyectos comunitarios, metodologías y escenarios. Esto representa una de las tensiones con la educación oficial, la normatividad es rígida con los horarios y tiempos dedicados a las asignaturas. En la educación propia se dispone de lugares significativos: como la huerta, sitios sagrados, la tulpa, la minga y rituales. En estos espacios enseñan geografía, historia, matemáticas, entre otras. Aun con las restricciones del Estado, algunos territorios ancestrales trabajan con el calendario propio, haciendo uso al derecho de la autonomía en los PEC, y cumpliendo con las asignaturas oficiales y contenidos de la cosmovisión ancestral:

(...) Nuestro proyecto responde a las necesidades del contexto comunitario, en términos de fortalecimiento de valores como el respeto a madre tierra, el buen uso de los recursos naturales, que los jóvenes entiendan el valor de la madre tierra y debe respetar, cultivarla, aprovecharla, hacer uso de ella de la manera más respetuosa, (...) porque depende de eso el bienestar colectivo, estos resultados, sabemos que son a mediano y largo plazo en este proceso educativo (entrevista pedagogo nasa, 2018).

La cosmovisión une el PEC con el Plan de Vida, y se proyecta un futuro deseado con la madre tierra, entenderse en ella; la concepción Madre Tierra fue elaborada en miles años, creando la conciencia tierra para posibles futuros, diferentes a las expectativas de futuro occidental; el primero tiene arraigo ancestral y naturocentrista; el segundo, se mueve hacia mundos imaginados sin control. Ese es el pensamiento indígena, entendido como el conjunto de saberes propios, prácticos y situados en la concepción cultural de cada pueblo milenario, han logrado construir futuros impulsando transformaciones sociales positivas, demostrando capacidad de agenciamiento colectivo y su contribución para preservar el medio ambiente, construir autonomías y resistencia cultural.

En este contexto, traer de vuelta la educación propia fue un triunfo del CRIC, que le permitió fijar derroteros para las futuras generaciones, partir de los principios: unidad, territorio, cultura y autonomía; los PEC en sí mismos reivindican los valores culturales, que se expresan en la plataforma política del CRIC, indispensables en la lucha por la autonomía territorial, epistémica y cultural, escenario de resistencia para restablecer códigos de la cosmovisión como la Ley de Origen, el idioma propio, el gobierno propio, la justicia propia y el buen vivir comunitario como cultura autónoma:

No ha sido posible destruir completamente la vida social autónoma de los grupos subordinados, que es fundamental para la producción de un discurso oculto. Las grandes formas históricas de dominación no sólo generan resentimientos, despojos y humillaciones que les dan a los subordinados, por decirlo así, algo de qué hablar; también son incapaces de impedir la creación de un espacio social independiente en el cual los subordinados pueden hablar con relativa seguridad (Scott, 2000, pp. 111-112).

La autonomía cultural indígena permite crear estrategias de resistencia a la cooptación ideológica subvirtiendo el dominio por el control social del territorio, protegiendo lugares sagrados de colonos, grupos armados, cultivos ilícitos y; pasando de la resistencia a la autodeterminación territorial, superando parte de los conflictos en los territorios ancestrales. La educación propia es la base de la resistencia indígena y los valores culturales.

Procesos de educación autónomos en los territorios ancestrales

Los resguardos y comunidades presentan condiciones climáticas, geográficas, ambientales, sociales y económicas diferentes. En ese sentido, los contenidos del PEC, pueden diferir de un resguardo 
a otro; esto es, democratización de la educación propia sin cambiar la filosofía en sus pilares de conocimiento en la educación propia, como vemos en el figura 1.

\section{Figura 1}

Campos de conocimiento

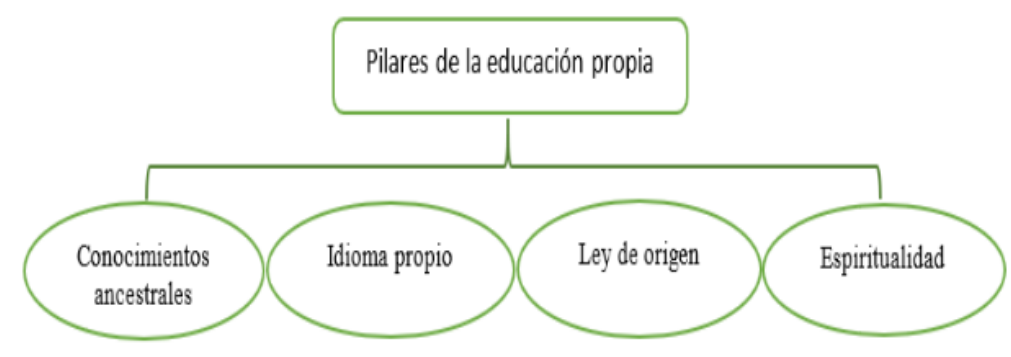

Nota. Estos campos constituyen ejes de la educación en el pueblo nasa.

Fuente. Elaboración propia, basado en entrevistas.

Los pilares se integran a las asignaturas oficiales o currículos académicos de manera transversal, especialmente en la primaria. Ahora veremos de manera sucinta lo que dice cada pilar para hacernos una idea. Pero, antes socializamos los escenarios donde se llevan a cabo los proyectos de educación autónomos, que difieren de los oficiales.

Wasak Kwewesx ${ }^{9}$ - Semillas de Vida-, es el espacio donde se habla de educación propia, se puede traducir como casa de pensamiento indígena, es un proceso autónomo y diferenciado al escolarizado. La intencionalidad política del Wasak Kwewesx es la enseñanza del idioma propia, la cultura y la espiritualidad nasa. La familia lleva los niños convencida de que, la educación propia es la que le conviene a sus hijos, el proceso formativo dura entre 20 a 23 años; allí conocen a fondo lo que es: cosmovisión, Ley de Origen, espiritualidad, cultura, política comunitaria, liderazgo, economía alternativa, gobierno propio; y, la cultura política occidental y formas de gobierno, como sostiene la sabedora Nasa:

(...) Ellos van a conocer, a aprender, a vivir desde la cosmovisión, serán las personas que a futuro van a estar al frente de toda la organización en los diferentes espacios, que sean nuestros tuthenas (consejeros), en las gobernaciones, alcaldías, los consejos municipales, el hecho de que vayan a una educación propia no quiere decir que no vayan a aprender las letras, los números, solo que primero van enraizar todo la cultura propia, luego podrán asumir lo de afuera, porque el reto es que puedan ejercer en ambos espacios, estar en una alcaldía, una gobernación, un consejo municipal sin perder la autonomía indígena, su conocimiento y su arraigo (entrevista, realizada en 2018).

La cosmovisión indígena establece una visión de la vida más próxima con la realidad que viven los pueblos de origen en los territorios ancestrales, no solo en la forma de percibir el origen de la vida; espacio, tiempo, territorio, sentido y las relaciones con la naturaleza, sino para transformar las relaciones con el entorno sociocultural; buscar nuevas formas de existencia para garantizar pervivir física y culturalmente; ejercer el derecho en la educación define la relación entre grupos étnicos con la cultura occidental, sobre las decisiones de asumir el control de la cultura propia, emanciparse, aunque han apropiado conceptos occidentales, logran adaptarlos a la cosmovisión. En este sentido, la educación propia enriquece los contenidos y procesos comunitarios.

Veamos ahora los pilares de la educación propia desde la perspectiva episteme raizal-ancestral indígena, para contrastarla con la occidental, no con la intención de validar la cosmovisión ancestral desde el pensamiento occidental, sino desde la cosmovisión que la produce. No es ético seguir

9 El indígena Marco Yule y su compañera, Carmen Vitonas, retoman el escenario Wasak Kwewesx preocupados porque la educación institucional no fortalece los principios del Nasa, se pierden las prácticas culturales, la lengua propia y la espiritualidad; surge la necesidad de rescatar los valores culturales en un espacio más tradicional enfocado en los valores, la identidad y la lengua propia. 
subalternizando e invalidando saberes diferentes al occidental. Estoy convencido que el conocimiento ancestral es tan válido como el europeo, el africano, asiático o cualquier otro, no se pueden ignorar, simplemente son diferentes; Igualmente, tenemos que reconocer desde América Latina lo que producen no solo "nuestros" intelectuales académicos, sino nuestros originarios. Las investigaciones deben ser sensibles y respetuosas con otras formas de producir conocimiento que no sabemos, ni conocemos y mucho menos entendemos.

Con lo anterior, plantearnos el pensamiento indígenas Nasa del Cauca, que también se encuentran en varias regiones del país, miraremos cada pilar sociocultural de la educación propia en clave episteme rizal-ancestral con la pregunta: ¿Es posible una episteme raizal ancestral indígena, que sustente la educación propia?

\section{Pilar: conocimiento ancestral -cosmovisión indígena}

La forma de ver el mundo y viene de la ley de Origen, es la narración de la historia que cuenta lo que sucedió cuando surgió el universo. Cada cultura tiene su narración a nivel político, cultural y religioso. Al originarse el mundo y al moldear la vida de los seres para una mejor relación y convivencia, surgen los mandatos los cuales constituyen -en nuestro caso- la Ley de Origen. La cosmovisión se halla pues, en estrecha con la apropiación simbólica del territorio y las lecturas culturales de los fenómenos y procesos en los que está inmerso determinado grupo social ${ }^{10}$ (Cisco, 2014).

El conocimiento ancestral ha perdurado más de 500 años, los españoles llegaron con un supuesto proyecto civilatorio que suprimió parte del conocimiento ancestral, los indígenas vieron amenazado su legado y lo ocultaron, mucho después, el CRIC, utilizando la cosmovisión como método de indagación lo recupera y revitaliza. El conocimiento ancestral expresa la resistencia milenaria en el pensamiento de la estirpe indígena posicionándolo en los PEC para ser compartido entre los pueblos.

(...) Las condiciones para lograr un buen vivir comunitario centrado en la unidad, diálogo, reciprocidad o correspondencia; también en el fortalecimiento y construcción de autonomía, así como la capacidad para proyectarse y articularse a otras sociedades respetando los derechos de todos (SEIP, 2013, p. 20).

La cosmovisión como metodología de auto-indagación recupera los saberes de la medicina nativa, la espiritualidad y las prácticas rituales, entre otros; asimismo, hace referencia a la cosmización de la existencia, en donde cosmos, vida y espacio físico son uno solo, "Ilenos de acontecimientos ritualizados con sentido vital permanente para conservar la armonía y el equilibrio" (SEIP, 2013, p. 28), a través de la cosmovivencia y la cosmoacción (acuñadas por los nasa), formas de coexistencia, vincularidad y armonía con la naturaleza, y las acciones son orientadas por la Ley de Origen.

\section{Pilar: idioma propio, nasa yuwe ${ }^{11}$}

El nasayuwe es la lengua madre del pueblo nasa, determina la relación con los espacios sagrados y espirituales en el territorio, facilita la comunicación en mingas donde practican la ritualidad, es la representación de la historia, está escrito en la mente y el corazón, los tejidos trenzados por las mujeres dejan inscritos el alfabeto y los símbolos de la escritura nasa (entrevista consejero nasa, 2018).

Tejer significa estar en contacto con los espíritus de la naturaleza y construir conocimientos, la mejor forma es el idioma nasayuwe para enseñar el significado de las palabras en coherencia con la cosmovisión, es bastón de la resistencia y la afirmación de la identidad cultural, a través del cual fluye el espíritu y el conocimiento para construir los PEC.

10 Recuperado el 27 de marzo de 2018 de https://bit.ly/2ZpQHOI

11 La ONIC establece que existen 102 pueblos indígenas, y solo 65 lo hablan la lengua materna; algunos lo hablan, escriben y entienden; otros solo lo hablan, pero no lo escriben; y, otros lo entienden, pero no lo hablan. 


\section{Pilar: ley de origen ${ }^{12}$}

La Ley de Origen, es legado de nuestros antepasados, significa: pensar, sentir, vivir con el corazón, desde nuestros y valores espirituales. (...) El pensar indígena debe ser un pensar del sentimiento, desde la espiritualidad, las prácticas, y usos de su cultura y estructurado en la lógica de la paridad (...).

La Ley de Origen es la fuente de los saberes que dan forma a la cultura (historia, política, autoridad, espiritualidad, organización social, salud, valores), que estructuran los PEC en los territorios y las comunidades.

\section{Pilar: espiritualidad ancestral}

La espiritualidad fortalece interna, física y culturalmente, siempre se realizan armonizaciones con plantas sagradas antes de reuniones, mingas, círculos de palabra, mambeo, actividades escolares, para que fluya el pensamiento, la creatividad, las relaciones armónicas, y sincronizarnos con los espíritus de la naturaleza y el cosmos, las ceremonias espirituales las dirige el the wala (entrevista, consejero nasa, 2018).

La espiritualidad está en sentir, pensar, actuar y relacionarse con el conjunto de seres y elementos de la naturaleza y el cosmos, a través de las prácticas rituales culturales interactúan y armonizan las relaciones el territorio augurando el bienestar comunitario.

EI PEC moviliza la episteme y las pedagogías que son la base para construir el conocimiento indígena, las metodologías y los pilares, un sistema alternativo, que el modelo occidental desacredita, no reconoce y advierte incompleto y exige validar con el modelo oficial considerado único, universal y valido, desconociendo otras formas de producir conocimiento, en palabras de Boaventura De Sousa (2009):

[...] El pensamiento occidental moderno es un pensamiento abismal. Éste consiste en un sistema de distinciones visibles e invisibles. Las distinciones invisibles son establecidas a través de líneas radícales que dividen la realidad social en dos universos, el universo de este lado de la línea y el universo del otro lado de la línea (p. 160).

Asimismo, la academia junto al estado colombiano excluye el conocimiento ancestral, desconoce su legitimidad en la educación propia cuando le exige cumplir con estándares de calidad; es decir, cooptarla con el modelo oficial, sin tener en cuenta las necesidades específicas de comunidades concretas e históricas en los territorios de origen que luchan por liberarse de epistemologías opresoras que:

[...] Al no reconocer como válidos otros tipos de conocimiento que no sean los producidos por la ciencia moderna, provocaron un epistemicidio masivo, es decir, la destrucción de una variedad inmensa de saberes que prevalecían principalmente del otro lado de la línea abisal, en las sociedades y sociabilidades coloniales (De Sousa, 2018, p. 36).

Los PEC colocan en escena conocimientos del mundo indígena, demostrando la validez y legitimidad frente al conocimiento oficial; en sentido práctico, resuelve problemas de salud curando enfermedades en las comunidades con la medicina ancestral, superan el analfabetismo en lugares donde no llega la educación oficial, por mencionar algunos ejemplos. De esta manera, la autonomía epistémica se legitima a la par de la occidental. A partir de estos presupuestos, la educación indígena no solo está atravesada por la cosmovisión, sino que, constituye un principio de autonomía cultural en la enseñanza-aprendizaje, mediada por diálogos de saberes, concepción epistemológica, alineada con la propuesta de las epistemologías del sur de Boaventura De Sousa Santos (2011):

Entiendo por epistemología del Sur el reclamo de nuevos procesos de producción y de valoración de conocimientos válidos, científicos y no científicos, y de nuevas relaciones entre diferentes

12 Recuperado el 27 de marzo de 2018: https://bit.ly/2ZpQHOIley 
tipos de conocimiento, a partir de las prácticas de las clases y grupos sociales que han sufrido de manera sistemática las injustas desigualdades y las discriminaciones causadas por el capitalismo y por el colonialismo (p. 25).

La episteme raizal-ancestral indígena subvierte desde dentro, como señala De Sousa, no se trata de desconocer el conocimiento científico, es cambiar la relación de dominio, para decidir qué tomo de afuera; por otra, visibilizar y/o rescatar aquellos saberes que se habían producido en "ausencias" por el pensamiento occidental moderno. Igualmente, desde la perspectiva de las epistemologías del sur, se visibiliza la diversidad de conocimientos de la Ley de Origen, la importancia de la memoria histórica en la conciencia y la construcción de futuros posibles, de acuerdo con Josep Fontana:

[...] Usar su capacidad para construir a partir de la diversidad de elementos del pasado a su alcance, presente recordados, que pueden contribuir a que la conciencia colectiva responda a los nuevos problemas que se le plantean [...] creando escenarios contrafactuales en que se puedan encajar e interpretar los hechos nuevos que se nos presentan (2006, p. 117).

Crear conciencia histórica es un trabajo pedagógico reflexivo del devenir histórico, los retos y exigencias colectivas para transformar las ideologías de la escuela y las condiciones opresoras, se necesita un pensamiento distinto como diría Freire, pensar auténticamente, pensar la realidad no estática, ni determinada, sino en un continúo dándose, exigiendo cada vez, implica descolocarse y recolocarse de manera diferente frente a la realidad para poder entender la historia. La historia como marco interpretativo y análisis contextual:

La historia es poder interpretar, construir la explicación y la comprensión que los fenómenos enfrentan en un momento dado, que puede ser un presente, con todo el peso que tiene la memoria histórica, la cual debe ser reconstruida; pero debe ser reconstruida no para llorar sobre la leche derramada, y construir un discurso de la nostalgia, sino simplemente para entender el presente (Zemelman, 2006, p. 29).

La historia tiene un papel fundamental en la educación propia que se consagra en liberar la psiquis del pensamiento colonizado, es educación desde y para los oprimidos; dice Paulo Freire en Pedagogía del Oprimido «La educación como práctica de la libertad, al contrario de aquella que es práctica de la dominación, implica la negación del hombre abstracto, aislado, desligado del mundo, así como la negación del mundo como una realidad ausente de los hombres» (1980, p. 88). La reflexión pedagógica sobre una cultura y mundo concretos, mediado por las relaciones sociales, culturales, lenguajes y con la naturaleza; conciencia histórica del mundo al que hace parte.

\section{Episteme Raizal-Ancestral Indígena}

Con lo anterior, se abordaron aspectos, instituyentes del pensamiento indígena que se recogen en lo que llamo episteme raizal-ancestral indígena; la cosmovisión como espacio de contenidos y sentidos sobre los que recae, en gran medida, el peso del conocimiento ancestral, en relación al presente sociohistórico, la información que se interpreta estableciendo espacios de relaciones que generan nuevas alternativas de acción que potencialmente pueden conducir a la construcción de su propia realidad, reivindicando la historia y cultura, antes negadas y silenciadas. 


\section{Figura 2}

Campos de la Episteme Raizal-Ancestral

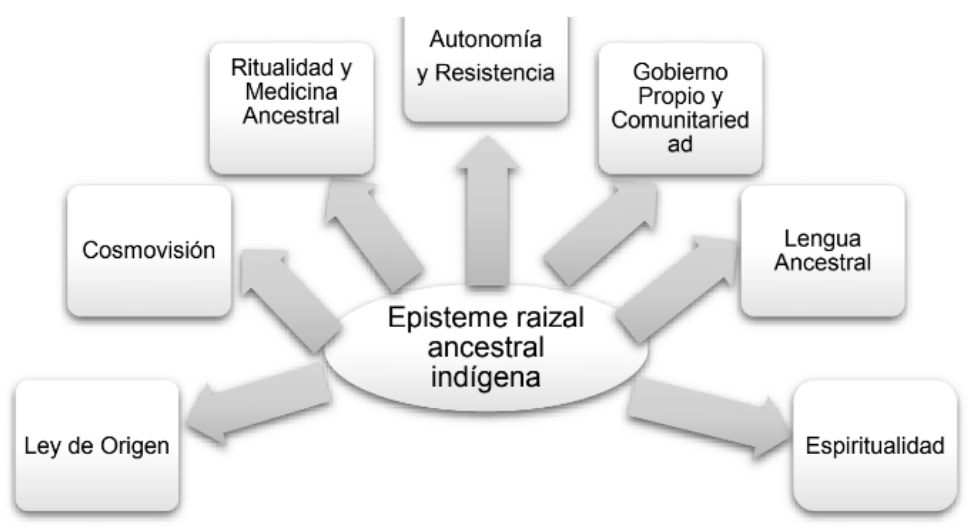

Fuente. Elaboración propia, basado en entrevistas, 2018.

Desde la perspectiva de los campos de la episteme raizal-ancestral indígena, se configura un sistema de pensamiento histórico, social y cultural que guía la pervivencia de los pueblos. A partir de estos presupuestos, la educación propia no solo está atravesada por campos, sino que, constituye un principio de conciencia autonómica en la enseñanza-aprendizaje, mediada por el diálogo de saberes, al respecto Boaventura De Sousa Santos, dice:

(...) Nuevas identidades regionales, nacionales y locales están emergiendo, construidas en torno a una nueva preeminencia de los derechos a las raíces. Tales localismos se refieren por igual a territorios reales o imaginados y a formas de vida y de sociabilidad fundadas en las relaciones frente a frente, en la proximidad y la interactividad (2003, p. 198).

Localismos que ubicamos en sectores indígenas que se renuevan a través de la re-territorialización simbólica, cultural y con lenguajes, que emergen del ocultamiento a que fueron sometidas con el propósito de silenciar la memoria colectiva, es la emergencia de las subjetividades indígenas y otras culturas [negros, campesinos y rom] también doblegadas por prácticas de dominación/exclusión y apropiación/violencia. Subjetividades que se rebelan a las imposiciones ideológicas occidentales, para autonombrarse e instituirse a partir de la autonomía epistémica, veamos las diferencias.

\section{Tabla 1}

Diferencias epistémicas entre las cosmovisiones

\begin{tabular}{|l|l|}
\hline \multicolumn{1}{|c|}{ Episteme occidental } & \multicolumn{1}{|l|}{ Episteme raizal-ancestral indígena } \\
\hline Parte del mundo externo & Parte de la Ley de Origen \\
\hline Dominio cognitiva & Sentipensante (Cognitiva y emocional) \\
\hline Realidad objetiva - neutral & Realidad subjetivada/vivencial/explora \\
\hline No-sentimiento/neutral & Afectiva-sensitiva /amorosa/implicativa \\
\hline Mide-controla-pronóstica & Inconmensurable/ armonizar \\
\hline Historia lineal o segmentada & $\begin{array}{l}\text { Memoria ancestral (presente pasado-pre- } \\
\text { sente futuro) }\end{array}$ \\
\hline a-espiritual & Espiritual \\
\hline Tiempo lineal & Tiempo en espiral \\
\hline La tierra le pertenece al hombre & $\begin{array}{l}\text { La humanidad le pertenece a la tierra } \\
\text { (Pachamama-pachacentrismo) }\end{array}$ \\
\hline Antropocentrismo & $\begin{array}{l}\text { Establece la interculturalidad étnicas } \\
\text { locales, diversas y planetarias }\end{array}$ \\
\hline Promueve una cultura universalizante & \\
\hline
\end{tabular}

Fuente. Elaboración propia basado en entrevistas, 2018. 
Desde esta perspectiva epistémica, el quehacer de la educación propia se orienta hacia la cosmovivencia y la cosmoacción para el Buen Vivir Comunitario, es una episteme que tiene definido los conocimientos en los pilares. Asimismo, podemos observar en la tabla 1, la importancia de los sentimientos, las sensaciones y las emociones; es una episteme del emocionar-racional - sentipensar-, a través de la cual, se coordinan acciones y relaciones; es otra forma de conocer, hacer, observarse en la experiencia compartida, mediatizada por relaciones generativas. Igualmente, representa un desafío para recuperar o despertar el conocimiento profundo de la naturaleza; crear conciencia de la necesidad de visibilizar el sujeto autónomo, crítico y colectivo que produce pensamiento para construir futuros desde una perspectiva diferente al capitalismo, un mundo condicionado por relaciones sociales basadas en transacciones del poder despótico.

\section{Conclusiones}

En este artículo quedan expuestas, apartes de la episteme raizal-ancestral indígena sobre la que se fundamenta la educación propia, sus contenidos, campos de conocimiento y pedagogías para la construcción de conocimiento, conciencia histórica e intencionalidades de las prácticas descolonizantes. Las pedagogías indígenas no remiten únicamente al currículo sino a la construcción de sujetos comunitarios para la cosmovivencia y la cosmoacción, que vivencian la educación en el Wasak Kwewesx con prácticas en huertas, mingas, asambleas, entre otras; espacios naturales e interactivos que inciden espiritual y psicoemocional en las y los niños. El aprendizaje no tiene límites y los entornos naturales ofrecen interiorizar la subjetividad comunitaria a través de pedagogías atractivas, creativas y lúdicas, permitiendo explorar a plenitud los sentidos al entrar en contacto con la naturaleza, Rousseau (citado por Carbonell, 2015), plantea que:

La naturaleza es el entorno y la esencia del niño, el mejor educador que garantiza su crecimiento; en consecuencia, hay que permitir que se deje influenciar por los beneficios de su hábitat natural, sin intervención ni interferencias de las personas adultas y de las instituciones que le imponen modelos artificiales que le alteran su orden natural (pp. 22-23).

Las características de los entornos naturales de aprendizaje promueven acercamientos para experimentar la parte sensomotriz y emocional; apropiar desde los sentimientos y conocimientos, emotivo a lo cognitivo, diferente al modelo tradicional, mostrando que, en este tipo de aprendizaje, se apropian más cualidades sobre los objetos de conocimiento, potenciando la curiosidad, la imaginación, los sentimientos y despertar facultades creativas observando los atributos de objetos en movimiento y tonalidades. En el aprendizaje mediado por entornos naturales se despierta el interés por el conocimiento, esto se puede constatar en la vida cotidiana de cualquier niño cuando la curiosidad le lleva a interesarse por un objeto que reclama su atención para percibirlo a plenitud.

Finalmente, la reflexión permite considerar aportes de los PEC a la formación oficial, en cuanto a la humanización de la educación, no pensarse desde lo monocerebral, sino desde un cerebro social, un sujeto que experimenta más allá de los sentidos, y que, se deben duplicar las facultades de percepción porque están adormecidas.

\section{Referencias}

Asociación de Cabildos Indígenas del Norte del Cauca. (2018). La historia y lucha de los Nasa. Serie de cartillas y mapas parlantes. ACIN.

Carbonell, J. (2015). Pedagogías del siglo XXI. Alternativas para la innovación educativa. Octaedro.

Consejo Regional Indígena del Cauca. (2004). ¿Qué pasaría si la escuela...? 30 años de construcción de una educación propia. Fuego Azul.

Consejo Regional Indígena del Cauca. (2007). Plan de vida regional de los pueblos Indígenas del cauca. CRIC. 
De Sousa, B. (2003). La caída del Ángelus Novus: Ensayos para una nueva teoría social y una nueva práctica política. Instituto Latinoamericano de Servicios Legales Alternativos (ILSA) y Universidad Nacional de Colombia (UNAL).

De Sousa, B. (2009). Una epistemología del sur. Siglo XXI. CLACSO.

De Sousa, B. (2011, Julio-septiembre). Epistemologías del sur. Revista Internacional de Filosofía Iberoamericana y Teoría Social, 16, 17-39. https://bit.ly/33XIvZ8

De Sousa, B. (2018). Introducción a las Epistemologías del Sur. En P. Meneses y K. Bidaseca (Coords.), Epistemologías del sur (pp.25-62). CLACSO.

Fals Borda, O (2015). Antología del pensamiento crítico colombiano contemporáneo. CLACSO.

Fontana, J. (2006). ¿Para qué sirve la historia en un tiempo en crisis? Ediciones Pensamiento Crítico.

Freire, P. (1980). Pedagogía del oprimido. Siglo XXI Editores.

González Casanova, P. (2009). De la sociología del poder a la sociología de la explotación. Pensar América Latina en el Siglo XXI. Siglo del Hombre Editores.

Maldonado, B. (2000). Los indios en las aulas: dinámicas de resistencia en Oaxaca. Centro INAH Oaxaca.

Quintín Lame, M. (1971). En defensa de mi raza. Rosca de investigación y acción social.

Quintín Lame, M. (1973). Las luchas del indio que bajó de la montaña al valle de la civilización. Editextos. LTDA.

Romero, F. (200, primer semestre). Manuel Quintín Lame: Sabiduría y saber escolar. Revista del Centro Cultural Universitario Aquelarre, 9, 59-82. https://bit.ly/365KjB0

Scott, J. (2004). Los dominados y el arte de la resistencia. Discursos ocultos. ERA.

Sistema de Educación Indígena Propio. (2013). Comisión nacional de trabajo y concertación de la educación para los pueblos indígenas. CRIC.

Wilches-Chaux, G. (2005). Proyecto nasa: la construcción del plan de vida de un pueblo que sueña. ARFO Editores.

Zemelman, H. (1998). Sujeto: existencia y potencia. Anthropos.

Zemelman, H. (2006). El conocimiento como desafío posible. IPECAL. 